\title{
Apropriação do patrimônio cultural na região portuária do Rio de Janeiro: políticas culturais entre a territorialidade e a exploração
}

\author{
Apropiación del patrimonio cultural de la región del puerto \\ de Rio de Janeiro: las políticas culturales entre territorialidad y explotación
}

\section{Appropriation of the cultural heritage in the port region of Rio de Janeiro: cultural policies between territoriality and exploitation}

\author{
Mariana Albinati'
}

\author{
Palavras chave: \\ Patrimônio cultural \\ Porto Maravilha \\ Territorialidade \\ Apropriação \\ Políticas culturais
}

Resumo:

O artigo se debruça sobre diferentes agentes e ações de política cultural que disputam, no contexto do projeto Porto Maravilha, os discursos e práticas acerca da cultura na Zona Portuária da cidade do Rio de Janeiro. Nesse sentido, coloca em discussão as diferentes lógicas que operam a apropriação do patrimônio cultural materialmente situado ou simbolicamente referido na região: de um lado a lógica da territorialidade que, atuando em diversas escalas, é marcada pela apropriação simbólica, pelo sentido de pertencimento (diferente de propriedade) e pela produção de bens comuns urbanos; de outro a lógica da exploração, marcada pela apropriação privada do capital simbólico coletivo produzido por grupos culturalmente subordinados em políticas culturais promovidas por e para grupos dominantes. Para tanto, parte-se de um entendimento ampliado acerca das políticas culturais, reconhecendo suas diferentes esferas de produção (institucionais ou não, do Estado ou da sociedade civil), sem ignorar a posição privilegiada que o Estado - e a coalizão de poderes e favor da qual opera - detém na disputa pela legitimidade da expressão das diferentes culturas que o espaço urbano reúne. 


\section{Resumen:}

El artículo se centra en diferentes agentes y acciones de política cultural que disputan, en el contexto del proyecto Porto Maravilha, los discursos y prácticas acerca de la cultura en la Zona Portuaria de la ciudad de Rio de Janeiro. En este sentido, pone en discusión las diferentes lógicas que operan la apropiación del patrimonio cultural materialmente situado o simbólicamente referido en la región: de un lado la lógica de la territorialidad que, actuando en diversas escalas, está marcada por la apropiación simbólica, por el sentido de pertenencia (diferente de propiedad) y por la producción de bienes comunes urbanos; de otro la lógica de la explotación, marcada por la apropiación privada del capital simbólico colectivo producido por grupos culturalmente subordinados en políticas culturales promovidas por y para grupos dominantes. Para ello, se parte de un entendimiento ampliado acerca de las políticas culturales, reconociendo sus diferentes esferas de producción (institucionales o no, desde el Estado o de la sociedad civil), sin ignorar la posición privilegiada que el Estado - y la coalición de poderes en favor de la cual opera - detiene en la disputa por la legitimidad de la expresión de las diferentes culturas que el espacio urbano reúne.
Palabras clave:

Patrimônio cultural

Porto Maravilha

Territorialidad

Apropriación

Políticas culturales

\section{Keywords:}

Cultural heritage

Porto Maravilha

Territorialy

Social appopriation

Cultural policies

\section{Abstract:}

The article focuses on different agents and actions of cultural policy that, in the context of the Porto Maravilha project, dispute the discourses and practices about culture in the portuary zone of the city of Rio de Janeiro. Therefore, the article discuss the different logics that operate the appropriation of the cultural patrimony materially situated or symbolically referred to in the region: on the one hand the logic of territoriality that, acting on several scales, is marked by symbolic appropriation, by the sense of belonging (different from property) and the production of urban common goods; on the other, the logic of exploitation, marked by the private appropriation of the collective symbolic capital produced by culturally subordinated groups in cultural policies promoted by and for dominant groups. To do so, this piece is based on an expanded understanding of cultural policies, recognizing their different spheres of production (institutional or not, from the state or civil society), without ignoring the privileged position that the state - and the coalition of powers and favor of which it operates - holds in the dispute for the legitimacy of the expression of the different cultures that the urban space gathers. 


\section{Apropriação do patrimônio cultural na região portuária do Rio de Janeiro: políticas culturais entre a territorialidade e a exploração}

\begin{abstract}
A Zona Portuária do Rio de Janeiro, onde desde 2009 está em curso a Operação Urbana Porto Maravilha, é um importante espaço de referência da produção de bens do patrimônio cultural material e imaterial. A região é frequentemente narrada como cenário do surgimento do samba, dentre outras expressões culturais de herança africana, que a fizeram conhecida como Pequena África, nome criado na década de 1920 pelo compositor Heitor dos Prazeres. Abriga ainda uma Área de Proteção do Ambiente Cultural (APAC) voltada para a preservação de edificações e usos, além de constituir um campo de pesquisas arqueológicas com achados de relevância mundial. Encontrado através de escavações arqueológicas realizadas em meio às obras do Porto Maravilha em 2011, o Cais do Valongo, porto que recebeu o maior número de africanos escravizados na América Latina, foi inscrito na lista do Patrimônio Cultural da Humanidade da UNESCO em 2017, reconhecido como sítio histórico sensível e maior referência para a memória da diáspora africana fora do continente.
\end{abstract}

A Operação Urbana Porto Maravilha coloca a região correspondente aos bairros da Saúde, Gamboa e Santo Cristo sob gestão de um consórcio de construtoras privadas por 15 anos, podendo ser tomada como exemplo da chamada governança empreendedorista neoliberal (SANTOS JÚNIOR, 2015), fruto do processo atual de reorganização capitalista, onde se ampliam as bases espaciais da acumulação, através de destruição/criação de estruturas urbanas e da sua disponibilização aos agentes do mercado. Os aspectos simbólicos que compõem essas estratégias de novo tipo ganham relevo em uma sociedade marcada pela centralidade da cultura, onde se pode observar a aproximação crescente entre a gestão urbana e as políticas econômicas e culturais, produzindo novos sentidos para os processos de patrimonialização de objetos, memórias e práticas culturais.

A reestruturação em curso na Zona Portuária pode ser considerada um projeto de gentrificação do lugar, e, nesse sentido, a lida do Porto Maravilha com as territorialidades estabelecidas por agentes das classes populares na região, relações de pertencimento e identidade cultural, objetiva converter esses conteúdos simbólicos em atrativos para os novos públicos - e capitais - a que o projeto se destina. Para tanto, os agentes envolvidos no empreendimento lançam mão de uma construção discursiva que, ao mesmo tempo, constrói a ideia da Zona Portuária como espaço vazio e decadente - justificando assim a necessidade de sua renovação e se apóia em aspectos da cultura local para legitimar suas ações e fomentar o ambiente multicultural - com ingredientes do cosmopolitismo misturados a aspectos selecionados e controlados da cultura popular - que marca as novas capitais globais.

Embora para o projeto isotópico, capitaneado pelo Estado segundo interesses de mercado, o patrimônio cultural seja encarado de forma utilitária com fins econômicos e de legitimação política, para uma série de outros agentes que constituem a região portuária como território carregado de simbologias e afetos, a patrimonialização de objetos, práticas culturais e referências históricas, oficializada ou não pelos órgãos do patrimônio, está ligada a outra ordem, a da territorialidade ou da identificação com seu espaço de vida e construção subjetiva.

Em um cenário de forte intervenção nas dinâmicas espaciais da região, diferentes agentes e ações de política cultural participam da disputa em torno da significação e apropriação do patrimônio cultural na Zona 
Portuária do Rio de Janeiro. Este texto tem por objetivo identificar e propor reflexões sobre duas lógicas distintas que condicionam diferentes práticas de apropriação do patrimônio cultural espacialmente situado ou referenciado na região, nos bairros históricos da Gamboa, Saúde e Santo Cristo. Em primeiro lugar, a lógica da territorialidade, que marca processos em que o patrimônio é apropriado como elemento constituinte do sentimento de pertencimento ao território, como referência para a constituição simbólica de sujeitos e grupos e sua relação com o espaço do entorno do Porto da cidade. Em segundo lugar, a lógica da exploração ou da espoliação, predominante nos projetos e ações em que o patrimônio, material e imaterial, é entendido como ativo econômico, não importando sua existência ativa enquanto elemento de registro de movimentos estéticos e processos construtivos, de memória e reflexão histórica, de expressão cultural e afirmação de identidades, mas sim o aspecto multicultural que empresta aos espaços mercantilizados na nova rodada de apropriação capitalista do espaço.

A palavra apropriação, nessas duas lógicas, apresenta significados opostos: quando identificada com a territorialidade, se refere ao estabelecimento de laços afetivos e de pertencimento; já na lógica da exploração, significa a tomada indevida de posse sobre algo. De um lado, pertencimento, identidade, liberdade e produção de comuns. De outro, posse, captura, privatização e mercantilização de comuns.

As disputas em torno do patrimônio integram políticas culturais produzidas por diferentes agentes que atuam sobre a região, em esferas institucionais ou não, do Estado ou da sociedade civil. Vale salientar aqui a opção por um conceito amplo de políticas culturais, entendendo que práticas culturais (valores, visões de mundo, formas de expressão, etc.) fazem parte do cotidiano dos diversos grupos sociais e que posicionamentos tomados tanto pelos grupos como pelo Estado determinam a valorização, o estímulo e a disseminação de determinadas práticas, objetos e memórias, ao passo em que definem também a invisibilização, o constrangimento e a destruição de outras formas e fontes de expressão cultural.

A noção de políticas culturais diz respeito a ações organizadas que interferem na produção e preservação de memórias, objetos e práticas culturais, tendo como objetivo, mais ou menos explícito, limitar ou dinamizar a diversidade cultural e as várias experiências da alteridade. Nesse sentido, nota-se que "além de políticas culturais que se limitam a celebrar a diversidade sem tocar em seu conteúdo político - trabalho inócuo ou deliberadamente avesso à afirmação das diferenças -, há aquelas que promovem a desvalorização das experiências de alteridade, subordinando os seus sujeitos" (DOMINGUES; ALBINATI, 2017, p. 110).

Mesmo reconhecendo a multiplicidade dos agentes das políticas culturais, é fundamental notar a posição privilegiada que o Estado - e a coalizão de poderes a favor da qual opera - detém na disputa pela legitimidade da expressão das diferentes culturas que o espaço urbano reúne. Assim, a opção por um modelo de cidade que privilegia as relações entre cultura e economia, determinando o caráter empreendimentista nas políticas culturais e sua colagem utilitária às políticas urbanas, invisibiliza, constrange e por vezes destrói expressões de culturas que não se adequam ao modelo.

No contexto de um projeto avassalador como o Porto Maravilha, em que grandes interesses privados determinam os rumos de um território cuja relevância cultural e histórica vai muito além dos 5 milhões de metros quadrados localizados no centro do Rio de Janeiro (área compreendida pelo projeto), as disputas em torno da legitimidade das políticas culturais se acirram. Especialmente no momento em que, imersos em uma crise de governabilidade - uma saga que envolve es- 
peculação financeira, investigações de corrupção e mudanças na coalizão de poderes à frente do projeto -, o órgão gestor (CDURP) e o consórcio de empresas (Consórcio Porto Novo) que implementa a Operação Urbana já não sinalizam com apoio material para a realização de projetos culturais na região, diminuindo o seu papel na determinação direta das políticas culturais locais.

As disputas em torno das políticas culturais e, notadamente, das políticas de preservação do patrimônio ganharam ainda mais fôlego quando, em julho de 2017, foi divulgada pela UNESCO a inscrição do Cais do Valongo na lista do Patrimônio Mundial. Desde então, as três esferas do governo - Município, Estado e União - e os três poderes - executivo, legislativo e judiciário -, movimentos sociais, ONGs, pesquisadores, moradores da região, entre outros agentes que ali mantêm vínculos de territorialidade vêm participando da arena pública que discute e articula a construção de um espaço de memória vinculado ao sítio arqueológico. Embora a construção desse espaço cultural tenha sido afirmada como compromisso pela Prefeitura no dossiê de candidatura submetido à UNESCO, as definições sobre o seu projeto estão ainda em aberto e em disputa.

A fala de Luiz Eduardo Negrogum, presidente do Conselho Estadual dos Direitos do Negro - CEDINE, feita durante a audiência pública "Cais do Valongo: Patrimônio Cultural da Humanidade: E Agora?", promovida pela Procuradoria da República no Rio de Janeiro em agosto de 2017, demonstra as duas diferentes lógicas que operam a apropriação do patrimônio cultural na região portuária:

o que está em voga é apropriação dum território negro pelo negro, com a história do negro (...) e a Docas André Rebouças [onde se pleiteia construir o espaço cultural] hoje, hoje ela tem que ser única e exclusivamente, totalmente um espaço afrodescendente. Tem que ser a nossa história e se tiver que ter uma ONG ali pra gerir a nossa história, que seja uma ONG comprometida com a nossa história, que venha das nossas raízes, das nossas entranhas. Se não for por assim, meu querido, pra usar mais uma vez, pessoas usando a nossa história pra se apropriar, enriquecer, tchau e bença! [grifos nossos]".

Primeiramente, o depoimento traz a apropriação como constituidora de uma relação de territorialidade, ou seja, como dado imaterial que faz daquele território um território. Nesse sentido, a "apropriação dum território negro pelo negro" se refere a uma relação espacial de pertencimento, mas também de poder, dada a configuração específica do espaço da Zona Portuária como portador de referências à escravidão negra e seu legado de desigualdades nos dias presentes. No segundo momento, ao se referir a projetos não identificados com a história negra e que poderiam obter ganhos materiais através da sua atuação no referido território, a apropriação se refere à exploração de bens culturais imateriais pertencentes ao povo negro, mercantilizando o capital simbólico coletivo produzido por este grupo subordinado.

Um importante episódio que em 2015 mobilizou diversos agentes em torno das possibilidades de apropriação do patrimônio na Zona Portuária foi a resistência à apresentação da peça teatral João de Alabá e a Pequena África, um dos muitos projetos culturais que se utilizaram de uma narrativa pacificada do patrimônio aquela divulgada pelo Porto Maravilha e seu Circuito Histórico e Arqueológico da Herança Africana - a fim de captar parte das verbas que então convergiam para a dinamização da cena cultural da região.

Em junho de 2015, quando foi noticiada a estréia da Peça João Alabá e a Pequena África, com texto e direção de Alexei 
Waichenberg, o conflito entre as diferentes formas de apropriação da memória da escravidão negra veio à tona de forma especialmente vigorosal"'. A foto de uma atriz branca caracterizada para o papel de mãe de santo, que viveria na peça, repercutiu entre militantes do movimento negro, que organizaram um ato de repúdio ao espetáculo. Na página do ato na rede social Facebook ${ }^{1 \mathrm{~V}}$, o debate colocava a questão da escravidão no tempo presente, tratando fundamentalmente de racismo e apropriação cultural. O diretor do espetáculo, branco, assim como atriz retratada, chegou a se defender em algumas postagens, com afirmações que foram prontamente desconstruídas pelos militantes, que apontaram o conteúdo racista do projeto cultural e da sua defesa.

A direção do projeto Porto de Memórias, que encenou outras peças em espaços públicos e se preparava para encenar João de Alabá e a Pequena África na Pedra do Sal, se informou através das redes sociais sobre a indignação provocada e convocou uma reunião com os organizadores do ato, encontro realizado no Instituto Pretos Novos. Compareceram à reunião representantes da comunidade, do Candomblé e do movimento negro. $\mathrm{Na}$ ocasião, a militante negra Alessandra Nzinga, respondendo à queixa de que a mobilização visava denegrir o projeto e o espetáculo, afirmou: "Denegrir realmente é o que a gente quer, porque denegrir significa tornar negro. Denegrir pra gente não é ofensa, muito pelo contrário. $E$ é por isso que a gente está aqui: porque a gente quer denegrir esta peça"v.

O site Mamapress, que divulgou 0 vídeo, relatou os resultados da reunião:

os moradores da região da antiga Pequena África, representantes do Movimento Negro e representantes do Candomblé, além de artistas negros e negras, apresentaram as seguintes propostas à direção da peça, para dirimir a celeuma e indignação provocada pela publicação da foto de uma atriz branca, paramentada exoticamente de Yalorixá, que iria representar o papel principal na peça dedicada a louvar as tradições culturais negras da região: Retratação pública da propagação e exposição de foto e caracterização ofensiva das Religiões de Matrizes Africanas, que possam ser interpretadas como racismo. Substituição da atriz branca por uma atriz negra. Ou suspensão da apresentação para que seja reavaliada (ROMÃO, 2015, online).

Diante da resistência à peça, a pretensão do grupo em apresentá-la na Pedra do Sal não foi à frente e o espetáculo, primeiramente adiado para "reparos", terminou por ser apresentado em duas sessões no Centro Cultural da Light, patrocinadora do projeto, na Gamboa.

No dia em que o espetáculo seria apresentado, o movimento realizou na Pedra do Sal o Ato em Honra à Pequena África ${ }^{\mathrm{VI}}$, que reuniu diversas organizações de militância negra, não necessariamente situadas nos bairros portuários, mas que por sua origem racial guardam relações de territorialidade com aquela região e seu patrimônio cultural.

A Pedra do Sal, tombada como patrimônio cultural pelo INEPAC em 1987, reconhecida como o mais antigo monumento vinculado à história do samba carioca, é um espaço cobiçado tanto pelos grupos que dele se apropriam como referente identitário, como por aqueles que procuram capitalizar seus projetos associando-se a um espaço reconhecido e tradicionalmente muito frequentado. $\mathrm{O}$ caso do samba da Pedra do Sal é emblemático para a observação das disputas em torno do patrimônio cultural na Zona Portuária, uma vez que o samba vem sendo apontado por antigos frequentadores, moradores da região, como um espaço apropriado por agentes "de fora", o que desvirtua a territorialidade inicialmente estabelecida. 
O samba a que nos referimos acontece há cerca de dez anos, às segundas-feiras, aos pés da Pedra do Sal, em um largo contíguo ao Largo da Prainha, que também abriga uma série de eventos musicais. No mesmo espaço físico, porém em dias diferentes da semana, outros grupos musicais se apresentam ali, o que condiciona especialidades facilmente distinguíveis para o observador externo e mais ainda pelos moradores que usam o espaço cotidianamente. Apontado como um importante espaço de sociabilidade e lazer para os moradores da região, o samba de segunda-feira foi reconfigurado a partir da chegada do Porto Maravilha e dos novos agentes que a Operação atrai para o território. Depoimentos de agentes culturais da região revelam as fissuras no samba enquanto um bem comum urbano:

Samba na Pedra do Sal foi um samba que era gostoso de se ir. Hoje não é mais... O de segunda. O de sexta é muito gringo, você não conhece ninguém, mas a segunda já era legal. Você chegava lá e conhecia todo mundo! $\mathrm{E}$ até ia até a galera que não gostava de samba (...) A roda de samba tem oito anos ali, são os mesmos músicos, mas com a revitalização o público se renovou, mudou muito. ${ }^{\text {VII }}$

Hoje eu não gosto de frequentar a Prainha. Porque tem lugares e pessoas ali que são experts... Ali não são eventos nossos. (...) O problema é que esse pessoal, os produtores culturais, recebe dinheiro pra fazer esses eventos culturais - esse pessoal paraquedista - e morador mesmo não vai. Porque pro morador aquilo não faz parte da sua cultura. VIII

Ambos os exemplos trazidos, da resistência à peça João de Alabá e do incômodo dos antigos frequentadores com a reconfiguração do público do samba da Pedra do Sal, demonstram a percepção, por parte dos agentes culturais que guardam vínculos de territorialidade com a região, das consequências do projeto de renovação urbana quanto à apropriação ou captura dos bens comuns urbanos que produzem. No caso da peça, a crítica é direcionada à apropriação racista de elementos do patrimônio negro e à exploração econômica do capital simbólico coletivo desse grupo social - suas memórias, história e produção cultural - por agentes externos. A mobilização de agentes do movimento negro contrária à encenação da peça, um movimento de defesa de território e tomada do patrimônio para si, evidencia a necessidade de que o protagonismo na definição dos significados e políticas de preservação do patrimônio seja daqueles agentes para quem as memórias, objetos e práticas patrimonializados são mais significativos, colocando em evidência a questão dos limites no acesso a determinados comuns.

No caso do samba da Pedra do Sal, embora o comum não se desfaça com a chegada dos novos usuários, que inclusive são atraídos por suas qualidades - o espaço festivo de encontro com a cultura negra, o ambiente amistoso onde "todo mundo se conhece" -, o acesso franqueado aos novos frequentadores degrada esse comum, que deixa inclusive de ser compartilhado por parte do grupo que o criou. David Harvey nos lembra que "nem todas as formas do comum requerem acesso livre" (HARVEY, 2014, p.142), no entanto, por ser produzido em um espaço público, um largo no sopé da Pedra do Sal, o samba de segunda-feira, enquanto um comum urbano, não pode restringir o acesso a outros grupos que queiram dele participar.

Além da questão da degradação do seu valor de uso, o problema do acesso aos bens comuns urbanos se agrava quando esses comuns possibilitam a assimilação de valor de troca. Ainda mais nos casos em que agentes externos procuram mercantilizar determinados comuns, entendendo-os como capital simbólico coletivo passível de apropriação privada. 
O patrimônio é um objeto de disputa especialmente delicado, pela potência que combina enquanto símbolo de resistência de grupos sociais subordinados, a que os projeto renovadores costumam expulsar, e também como "diferencial" - aqui vale o sentido comercial da palavra - que agrega valor de troca no processo de mercantilização das cidades que se almeja converter em capitais globais através de um urbanismo neoliberal.

Reginaldo dos Santos Gonçalves questiona o sentido da negação da mercantilização nos discursos do campo do patrimônio cultural: "Há um esforço constante e sempre precário de manter os objetos classificados como "patrimônio" fora do alcance da contaminação que o mercado possa desencadear. Mas, paradoxalmente, esses objetos são, enquanto patrimônio, um efeito mesmo do mercado" (GOLÇALVES, 2007, p. 243). Porém, se as "incontornáveis e ambíguas relações com o mercado" são parte constituinte das políticas de preservação no mundo moderno, quais os limites para a exploração econômica do patrimônio cultural? Quais os riscos que essa relação coloca para a sua existência enquanto um comum? Que grupos podem ou não participar de sua comunalização e quais os que podem ativá-lo como capital?

O foco da crítica aqui tecida à apropriação privada do patrimônio cultural enquanto um bem comum urbano não está no seu uso para obtenção de valor de troca, mas sim na possibilidade de que a apropriação privada desse valor de troca seja realizada por agentes que não compõem o coletivo que produziu o comum ou para quem ele é mais significativo do ponto de vista do seu valor de uso. O problema reside nos modos de exploração capitalista do patrimônio que expropriam de seus agentes a possibilidade de usufruírem desses comuns como valor de uso e/ou como valor de troca. O processo de gentrificação acarretado pelos projetos de renovação ur- bana, que retira dos espaços renovados as classes populares que lhes emprenharam de comuns de todos os tipos, exemplifica essas práticas de expropriação.

Um grupo comunitário que luta por manter a diversidade étnica em seu bairro e protegê-lo da gentrificação pode descobrir repentinamente que os preços (e os impostos) de suas propriedades aumentam à medida que os agentes imobiliários propagandeiam para os ricos o "caráter" multicultural, diversificado e movimentado de seu bairro. Quando o mercado concluísse seu trabalho destrutivo, não só os residentes originais seriam despojados do comum que eles haviam criado (sendo constantemente forçados pelo aumento dos aluguéis e dos impostos sobre a propriedade), como também o próprio comum já se teria degradado a ponto de tornar-se irreconhecível (HARVEY, 2014, p. 152).

A noção de capital simbólico coletivo (HARVEY, 2005) deriva do conceito de capital simbólico bourdiesiano, que entende os diferentes tipos de capitais, inclusive o econômico, como intercambiáveis. Um comum cultural pode ser capitalizado na forma de capital simbólico coletivo, proporcionando aos membros do grupo produtor recursos que têm valores diferentes nos diferentes campos. Pertencer ao grupo originário do samba de segunda-feira da Pedra do Sal, por exemplo, é fonte de prestígio e reconhecimento em determinados segmentos do campo cultural - por exemplo, entre os agentes que almejam participar daquele comum, mas não possuem os requisitos para tal - o que significa capital simbólico que, em última instância, pode ser em algum momento convertido em econômico. Porém, a predominância do valor de uso na criação do comum talvez seja o que lhe confere algum valor de troca, o que o transforma em capital simbólico coletivo. 
As políticas culturais de preservação do patrimônio, promovidas por organizações do Estado ou da sociedade civil, inseridas em um contexto de imbricação entre cultura e economia, privilegiam questões relacionadas ao consumo turístico e à "sustentabilidade" do patrimônio, ou seja, às estratégias para que dele se extraia valor de troca. Como afirma Gonçalves (2007, p.244),

Um prédio tombado como "patrimônio cultural" existe na medida em que se inibe ou se limita sua condição de mercadoria: não pode ser vendido ou não pode sofrer alterações. No entanto, essa sua condição de mercadoria está presente não apenas na possibilidade de ser alienado, mas efetivamente na sua condição de objeto de consumo turístico, portanto enquanto suporte de uma determinada imagem que é consumida: o passado nacional, a cultura popular, a cultura nativa, ou antigos bairros de uma cidade, como é o caso das "Áreas de Preservação Ambiental e Cultural" (as APACS) no Rio de Janeiro.

Uma dessas APACs, aliás, está situada na região portuária (APAC SAGAS) e foi alvo de projetos revitalizadores anteriores ao Porto Maravilha, quando não haviam sido desenterrados tantos registros da história da escravidão e quando a imagem para consumo turístico projetada pela Prefeitura do Rio de Janeiro era a de um conjunto remanescente de ocupação portuguesa e espanhola, características presentes em parte da ocupação do Morro da Conceição GUIMARÃES, 2014) e que ao serem evidenciadas procuravam também invisibilizar a presença negra na constituição daquele território portuário. A história da APAC SAGAS apenas ilustra o tipo de apropriação do patrimônio que os projetos renovadores levam a cabo, menos interessado no conteúdo dos objetos e práticas patrimonializados e nas relações de territorialidade que se estabelecem em torno desse patrimônio e mais no seu uso como signo da multiculturalidade que caracteriza as cidades globais. Nesse entendimento, o foco da política cultural não está no valor de uso do patrimônio, em sua existência enquanto comum, mas no seu potencial de geração de valor de troca, através da mercantilização da imagem ou da "experiência" de contato com os bens materiais e imateriais patrimonializados.

Se o patrimônio cultural pode ser encarado como um comum e, no caso do patrimônio inserido em espaços onde a governança neoliberal se impõe, como um bem comum urbano ameaçado, é importante notar que a chave de entendimento do conceito de bens comuns urbanos está na apropriação social. David Harvey denomina "bens comuns urbanos" aos frutos da produção coletiva de grupos sociais disponíveis para sua apropriação não mercantil (HARVEY, 2014). Não se trata simplesmente dos espaços públicos, pois, embora estes favoreçam a existência de práticas de comunalização, só se tornam comuns quando efetivamente apropriados e comunalizados por grupos sociais. O comum é, então, fruto da apropriação social, entendida, conforme Henri Lefebvre, como "modalidade superior de liberdade" (LEFEBVRE, 2008, p. 129), prática que transforma o que estava somente disponível em algo próprio no sentido subjetivo, tomado por usos/práticas que correspondem aos desejos e ao repertório simbólico dos usuários/praticantes.

O ambiente e a atratividade de uma cidade, por exemplo, é um produto coletivo de seus cidadãos, mas é o mercado do turismo que capitaliza comercialmente esse comum (...). Por meio de suas atividades e lutas cotidianas, os indivíduos e grupos sociais criam o mundo social da cidade ao mesmo tempo em que criam algo de comum que sirva de estrutura em que todos possam abrigar-se. Embora esse comum culturalmente criativo não possa ser destruído pelo uso, pode 
ser degradado e banalizado pela utilização abusiva (HAVEY, 2014, p. 146).

Embora seja um bem comum urbano, o conjunto de referências do patrimônio negro situadas ou referenciadas espacialmente na Zona Portuária carioca não pertence necessariamente a todos de forma igual, pois, conforme Harvey, a comunalização pode definir usos exclusivos por determinado grupo social ou parcial ou totalmente abertos a toda a sociedade (HARVEY, 2014). A população negra, que estabelece práticas cotidianas de comunalização desse patrimônio, para quem o seu valor de uso é mais representativo, deve ser então participar de forma privilegiada na definição da gestão do comum, que também requer certas proteções que garantam a sua preservação.

A lógica da exploração na lida com o patrimônio é ainda mais problemática quando serve à apropriação, por outros agentes, de comuns produzidos por grupos culturalmente subordinados. Ou seja, quando a apropriação privada do capital simbólico coletivo produzido por grupos subordinados é realizada através de políticas culturais promovidas por e para grupos dominantes em detrimento e contra os demais grupos sociais.

$\mathrm{Na}$ Zona Portuária carioca o risco maior da apropriação do patrimônio ligado à herança africana no bojo de um projeto gentrificador é a expulsão gradativa dos agentes para quem a história da escravidão é revivida cotidianamente, sendo ainda determinante de sua condição social subordinada. Agentes que produziram na região o território negro, repleto de expressões e referências culturais, de que outros grupos sociais - como o grupo que compõe a coalizão de poderes por trás do Porto MaraviIha - buscam agora se apropriar.

Outro risco a que é importante atentar é o da despolitização ou pacificação na interpretação desse patrimônio, fato que pode vir a ocorrer na nova rodada de disputas que o reconhecimento do Cais do Valongo estabelece, a depender da posição que o movimento negro consiga assumir nesse jogo, visando garantir sua participação prioritária na elaboração e gestão das políticas culturais. Desta forma, garantindo que a população negra possa se apropriar do patrimônio enquanto um comum, mas também enquanto capital simbólico, estando em condição também de captar os benefícios objetivos que certamente a gestão de um bem do Patrimônio da Humanidade pode vir a conferir.

Em um cenário de mercantilização das cidades, quem tem acesso a determinados bens comuns urbanos também pode se beneficiar da sua mercantilização, mesmo não intencionalmente e mesmo de forma subordinada, sob as condições colocadas pelo capitalismo contemporâneo e sua cartilha empreendimentista. Esse aproveitamento secundário (que não é o objetivo dos projetos de renovação urbana, mas pode ser aceito como um efeito colateral não maléfico) garante, muitas vezes, oportunidades melhor remuneradas ou mais rentáveis para pessoas e grupos sociais que mantém os comuns urbanos em circulação.

Como o discurso produzido para estimular a reapropriação capitalista da região portuária do Rio de Janeiro se utiliza dos signos da herança africana - fato que, aliás, deriva da mobilização política de agentes que se relacionam com essa herança - encarando-os como "diferencial" no sentido da obtenção de renda de monopólio (HARVEY, 2005) sobre o espaço, o mesmo grupo que promove a gentrificação do lugar precisa também estimular a permanência e a expressão cultural das populações que o qualificam através da sua produção de bens comuns urbanos.

O patrimônio, como bem define José Reginaldo Gonçalves, é uma categoria ambígua, "uma vez que liminarmente si- 
tuada entre o passado e o presente, entre o cosmos e a sociedade, entre a cultura e os indivíduos, entre a história e a memória" (2007, p.246). Nesse sentido, o cenário de disputas em torno da apropriação do patrimônio cultural na Zona Portuária carioca precisa ser encarado de forma dialética, pois envolve também ambiguidades e complexas relações entre valor de uso e valor de troca, bem comum e capital simbólico.

\section{Bibliografia}

DOMINGUES, João; ALBINATI, Mariana. Direitos culturais: diversidade e conflito produzindo a cidade. In: SANTOS JUNIOR, O. A. dos; NOVAES, P. R.; LACERDA, L.; WERNECK, M. (orgs.). Caderno Didático Políticas públicas e direito à cidade: programa interdisciplinar de formação de agentes sociais. Rio de Janeiro: Letra Capital, 2017.

GONÇALVES, José Reginaldo Santos. Os limites do patrimônio. In: LIMA FILHO; ECKERT; BELTRÃO (orgs.). Antropologia e Patrimônio Cultural: diálogos e desafios contemporâneos. Rio de Janeiro: Nova Letra, 2007.

GUIMARÃES, Roberta Sampaio. A utopia da Pequena África: Projetos urbanísticos, patrimônios e conflitos na Zona Portuária carioca. Rio de Janeiro: FGV, 2014

HARVEY, David. A produção capitalista do espaço. São Paulo: Annablume, 2005.

HARVEY, David. Cidades rebeldes: do direito à cidade à revolução urbana. São Paulo: Martins Fontes, 2014.

LEFEBVRE, Henry. A revolução urbana. Belo Horizonte: Editora UFMG, 2008.

ROMÃO, Marcos. Denegrir não é ofensa, queremos denegrir esta peça: "João Alabá e a Pequena África". Mamapress, 17 de jun. 2015 (online). Disponível em: $<$ https://mamapress.wordpress.com/2015/06/17/denegrir-nao-e-ofensa-queremos-denegrir-esta-peca-joao-alaba-e-a-pequena-africa/>.
SANTOS JUNIOR, Orlando Alves dos. Governança empreendedorista: a modernização neoliberal. In: RIBEIRO, Luiz Cesar de Queiroz (org.). Rio de Janeiro: transformações na ordem urbana. Rio de Janeiro: Letra Capital; Observatório das Metrópoles, 2015.
I Mariana Luscher Albinati. Doutora em Planejamento Urbano e Regional pelo IPPUR/Universidade Federal do Rio de Janeiro. Pesquisadora do Observatório das Metrópoles. Contato. marianaalbinati@yahoo.com.br

II Fala transcrita pela Procuradoria da República no Rio de Janeiro, obtida através de solicitação ao órgão.

III www.geledes.org.br/artistas-negras-somem-da-paisagem-do-rio-de-janeiro-de-2015-artistas-negras-protestam-na-pedra-do-sal/

IV www.facebook.com/events/853865534662910/permalink/858246834224780/

$\checkmark$ Fala extraída do vídeo disponível em www.youtube. com/watch?v=j48SbboBjiU

VI Vídeo sobre o Ato em Honra à Pequena África, disponível em www.youtube.com/watch?v=ku7IRVA4Z9|

VII Entrevista cedida à autora em janeiro de 2015.

VIII Entrevista cedida à autora em junho de 2015. 